\title{
The effects on Apgar scores and neonatal outcomes of switching from a combination of phenylephrine and ephedrine to phenylephrine alone as a prophylactic vasopressor during spinal anesthesia for cesarean section
}

\author{
Joo Yeon Jeon, In Ho Lee, Young Seok Jee, Pil Moo Lee, Seung In Park, and Hea-Jo Yoon
}

Department of Anesthesiology and Pain Medicine, Cheil General Hospital, Kwandong University Medical School, Seoul, Korea

Background: Ephedrine, unlike phenylephrine, has a dose-related propensity to depress fetal $\mathrm{pH}$ during spinal anesthesia during cesarean section. A low arterial umbilical cord $\mathrm{pH}$ has a strong association with neonatal mortality and morbidity. The purpose of this retrospective study was to investigate influences of vasopressor change on Apgar scores and adverse neonatal outcomes in cesarean section.

Methods: In obstetric anesthesia, we changed the prophylactic vasopressor from a combination of phenylephrine and ephedrine to phenylephrine alone in 2000. We evaluated the impact of vasopressor change on Apgar scores ( 1 and 5 $\mathrm{min}$ ), incidence of Apgar score < 7 ( 1 and $5 \mathrm{~min}$ ), neonatal seizure, continuous positive airway pressure (CPAP), intermittent positive pressure ventilation (IPPV), intraventricular hemorrhage (IVH), periventricular leucomalacia (PVL), and hypoxic ischemic encephalopathy (HIE) in low-risk elective cesarean sections during a period when the combination of phenylephrine and ephedrine was used (2008-2009, two years) and the period of phenylephrine use alone (20112012, two years).

Results: There were no differences in Apgar scores ( 1 and $5 \mathrm{~min}$ ), the incidence of 5 min Apgar score $<7$, neonatal seizure, CPAP, IPPV, IVH, PVL, and HIE between the two time periods. However, the incidence of 1 min Apgar $<7$ was decreased during the period of phenylephrine use compared with the period of phenylephrine and ephedrine use $(\mathrm{P}=0.002)$. Conclusions: Conversion from a combination of phenylephrine and ephedrine to phenylephrine alone as a prophylactic anti-hypotensive drug during spinal anesthesia for cesarean section in low-risk pregnancy may be associated with a significant decrease in the incidence of 1 min Apgar < 7. (Korean J Anesthesiol 2014; 67: 38-42)

Key Words: Apgar score, Cesarean section, Ephedrine, Neonatal outcomes, Phenylephrine, Spinal anesthesia.

Received: November 25, 2013. Revised: December 19, 2013. Accepted: December 26, 2013.

Corresponding author: Hea-Jo Yoon, M.D., Department of Anesthesiology and Pain Medicine, Cheil General Hospital, Kwandong University Medical School, 17, Seoae-ro 1-gil, Jung-gu, Seoul 100-380, Korea. Tel: 82-2-2000-7822, Fax: 82-2-2000-7477, E-mail: heajo7890@hanmail.net (c) This is an open-access article distributed under the terms of the Creative Commons Attribution Non-Commercial License (http:// creativecommons.org/licenses/by-nc/3.0/), which permits unrestricted non-commercial use, distribution, and reproduction in any medium, provided the original work is properly cited. 


\section{Introduction}

Hypotension is one of common complications in spinal anesthesia for cesarean section. The use of uterine displacement and volume preloading cannot effectively prevent hypotension after spinal anesthesia [1,2]. Therefore, a vasopressor, such as ephedrine or phenylephrine, may be necessary to prevent and treat hypotension. Conventionally, ephedrine was the drug of choice for hypotension during spinal anesthesia for cesarean section. However, a number of studies have suggested ephedrine has a dose-related propensity to depress fetal $\mathrm{pH}$ and base excess (BE) in comparison to phenylephrine [3-5]. In addition, umbilical artery $\mathrm{pH}$ in a combination group of phenylephrine and ephedrine was lower than that of phenylephrine alone group $[6,7]$. When diverse combinations of phenylephrine and ephedrine were infused to maintain arterial blood pressure during spinal anesthesia for cesarean section, as the proportion of phenylephrine decreased and the proportion of ephedrine increased, decreases were observed in fetal $\mathrm{pH}, \mathrm{BE}$ and umbilical arterial oxygen content [7]. Fetal acidosis identified by umbilical artery $\mathrm{pH}$ in spinal anesthesia for cesarean section is mainly the result of metabolic acidosis with low BE [7-10]. The metabolic component of acidosis could contribute to the increased risk of adverse outcomes instead of the respiratory component [7-10].

There is no study about impact of vasopressors on Apgar scores and neonatal outcomes in a large population base. We therefore used a large patient population with low-risk pregnancies to further delineate the impact of vasopressor changes in elective cesarean section on Apgar scores and neonatal outcomes.

\section{Materials and Methods}

For obstetric anesthesia, we switched from using a combination of phenylephrine and ephedrine to phenylephrine alone as a prophylactic vasopressor for cesarean sections in 2010. We conducted a retrospective cohort study in our hospital for two time periods, from 2008-2009 and 2011-2012. The study was reviewed and approved by our hospital's Institutional Review Board. We extracted data from the anesthetic, obstetric, operational and neonatal records, including the database of the neonatal intensive care unit. In all, 11,078 cesarean sections were done during the study period (2945 in 2008, 2674 in 2009, 2730 in 2011, and 2729 in 2012).

For the current analysis, we selected elective cesarean sections by spinal anesthesia in mothers who experienced no labor pain before anesthesia and who had a maternal age between 19 and 44 years, a full-term pregnancy ( $\geq 37$ week's gestation), and infants weighing $\geq 2,500 \mathrm{~g}$ without any known fetal anomalies. We also included cesarean sections indicated for a previous sec- tion, breech presentation, transverse lie presentation, cephalopelvic disproportion, and surgery scarring. We excluded cases in which spinal anesthesia was converted to mask or general anesthesia or those where any sedative was administered before the delivery of the newborn. We also excluded cesarean sections with indications of twins, myoma in the uterus, intrauterine growth retardation, oligohydroamnios, and placenta previa. Mothers with hypertension (including pregnancy-induced hypertension), diabetes mellitus (including gestational diabetes mellitus), cardiovascular, cerebrovascular, respiratory, or renal disease or those who were American Society of Anesthesiologists physical status III or greater were also excluded.

Patients were not premedicated, and they received lactated Ringer's solution at the full rate upon entering the operating room. Standard noninvasive monitoring was applied. We allowed the patients to rest undisturbed in the supine position for several minutes while their blood pressure (BP) was measured at least twice every minute to establish a baseline. Spinal anesthesia was administered with the patients in the left lateral position at the L3-4 or L4-5 vertebral interspace, and 0.5\% hyperbaric bupivacaine $10 \mathrm{mg}$ and fentanyl $15 \mu \mathrm{g}$ were injected intrathecally using a 25-gauge pencil point needle (Pencan ${ }^{\circledR}, \mathrm{B} /$ Braun, Melsungen, Germany). After spinal anesthesia, phenylephrine (Phenylephrine $\mathrm{HCl}^{\circledR}$; Hana Pharmaceuticals, Seoul, Korea) and ephedrine (Ephedrine $\mathrm{HCl}^{\circledR}$; Daewon Pharmaceuticals, Seoul, Korea) were infused at a rate of $25 \mu \mathrm{g} / \mathrm{min}$ and at a rate of $2 \mathrm{mg} /$ min, respectively, in 2008-2009 (Group P+E). Instead of phenylephrine and ephedrine, phenylephrine alone was infused at a rate of $50 \mu \mathrm{g} / \mathrm{min}$ in 2011-2012 (Group P). We checked patients' $\mathrm{BP}$ and heart rate $(\mathrm{HR})$ at 1-min intervals until delivery. If the systolic blood pressure (SBP) was above the baseline, the infusion was stopped; if it was at or below the baseline, the infusion was continued. Hypotension, defined as a SBP $\leq 80 \%$ of baseline SBP despite the phenylephrine infusion, was treated with a bolus of phenylephrine $100 \mu \mathrm{g}$. Bradycardia was defined as $\mathrm{HR}<$ 50 beats/min and was treated with glycopyrrolate $0.2 \mathrm{mg}$. After delivery, Apgar scores at 1 and 5 min were measured by an anesthesiology specialist or by $2^{\text {nd }}$-year or higher residents.

We compared the Apgar scores and neonatal outcomes in both groups during the two time periods (Group P+E; 20082009, Group P; 2011-2012). Data were expressed as mean \pm $\mathrm{SD}$, median (interquartile range) or number of patients (\%). Demographic data were analyzed using Student's t-test after the Kolmogorov-Smirnov normality test. Apgar scores were analyzed with MannWhitney U test. A comparison of the categorical variables was performed using $\chi^{2}$ analysis. The relative risk and 95\% confidence intervals were calculated when appropriate. Statistical analyses were performed with SigmaStat version 4.0 (San Jose, CA, USA). P values $<0.05$ were considered statistically significant. 
Table 1. Demographic and Labor Characteristics according to Vasopressor Use

\begin{tabular}{lccr}
\hline & $\begin{array}{c}\mathrm{P}+\mathrm{E} \\
(\mathrm{n}=1,693)\end{array}$ & $\begin{array}{c}\mathrm{P} \\
(\mathrm{n}=2,068)\end{array}$ & P value \\
\hline Maternal age (yr) & $32.2 \pm 3.9 *$ & $32.8 \pm 3.7$ & $<0.001$ \\
Maternal height (cm) & $162.9 \pm 3.7$ & $163.1 \pm 4.2$ & 0.126 \\
Maternal weight (kg) & $67.8 \pm 7.5$ & $68.0 \pm 8.5$ & 0.449 \\
Birth weight (g) & $3273 \pm 345$ & $3280 \pm 334$ & 0.529 \\
Gestational age (wk) & $38.6 \pm 1.2$ & $38.5 \pm 1.1$ & 0.267 \\
Nuchal cord (\%) & $295(17.4 \%)$ & $356(17.2 \%)$ & 0.900 \\
\hline
\end{tabular}

Data presented as mean \pm standard deviation, or number (\%). P+E: phenylephrine and ephedrine group, $\mathrm{P}$ : phenylephrine group. $* \mathrm{P}<0.05$ vs. group P.

\section{Results}

Baseline and obstetric characteristics of the study population are listed in Table 1. There were no statistically significant differences in maternal height, maternal weight, birth weight, gestational age, and incidence of a nuchal cord. However, the maternal age of Group P+E was lower than that of Group P $(\mathrm{P}<0.001)$.

The median value of the $1 \mathrm{~min}$ Apgar score and the $5 \mathrm{~min}$ Apgar score as well as the incidence of neonates with $5 \mathrm{~min}$ Apgar scores $<7$ were similar between the two groups (Table 2). Group P+E had a significantly increased incidence of neonates with 1 min Apgar $<7$ compared with Group P (relative risk $=0.39,95 \%$ confidence interval 0.21 to $0.70, \mathrm{P}=0.002$ ). The incidence of neonates with neonatal seizure, application of continuous positive airway pressure or intermittent positive pressure ventilation, intraventricular hemorrhage, periventricular leucomalacia, and hypoxic ischemic encephalopathy was similar between the two groups.

\section{Discussion}

We observed a significant decrease in the incidence of $1 \mathrm{~min}$ Apgar $<7$, but no decrease in the incidence of 5 min Apgar $<7$ or adverse neonatal outcomes were seen when the prophylactic vasopressor was changed from the combination of phenylephrine and ephedrine to phenylephrine alone in spinal anesthesia for elective cesarean section in low-risk pregnancy.

Cooper and Gowni [11] evaluated the impact of changing the vasopressor from ephedrine to phenylephrine as the first-line vasopressor on umbilical artery $\mathrm{pH}$ and the incidence of fetal acidosis for cesarean section regardless of the type of anesthesia with a study population of 1,009 deliveries. They found a small increase in umbilical artery $\mathrm{pH}$ and a small decrease in the incidence of fetal acidosis. They claimed the main reason for the improvement of the acid-base balance was improved obstetric management of the highest-risk patients instead of the vasopressor change between the time periods. In contrast, we studied
Table 2. Apgar Scores and Neonatal Outcomes according to Vasopressor Use

\begin{tabular}{lccc}
\hline & $\begin{array}{c}\mathrm{P}+\mathrm{E} \\
(\mathrm{n}=1,693)\end{array}$ & $\begin{array}{c}\mathrm{P} \\
(\mathrm{n}=2,068)\end{array}$ & P value \\
\hline 1 min Apgar & $8(8-9)$ & $8(8-9)$ & 0.450 \\
5 min Apgar & $9(9-10)$ & $9(9-10)$ & 0.545 \\
1 min Apgar $<7$ & $34(2.0 \%)^{*}$ & $16(0.8 \%)$ & 0.002 \\
5 min Apgar $<7$ & $1(0.1 \%)$ & 0 & 0.943 \\
Neonatal seizure & $3(0.2 \%)$ & 0 & 0.182 \\
CPAP, IPPV & $5(0.3 \%)$ & $7(0.3 \%)$ & 0.945 \\
IVH & $1(0.1 \%)$ & 0 & 0.920 \\
PVL & $1(0.1 \%)$ & 0 & 0.920 \\
HIE & $1(0.1 \%)$ & 0 & 0.920
\end{tabular}

$\overline{\text { Data are presented as median (interquantile range) or number (\%). CPAP: }}$ continuous positive airway pressure, IPPV: intermittent positive pressure ventilation, IVH: intraventricular hemorrhage, PVL: periventricular leucomalacia, HIE: hypoxic ischemic encephalopathy. P+E: phenylephrine and ephedrine group, $\mathrm{P}$ : phenylephrine group, ${ }^{*} \mathrm{P}<0.05$ vs. group $\mathrm{P}$.

low-risk pregnancy in spinal anesthesia to minimize unevaluated risk factors that could influence the neonatal outcomes between the time periods. Previous studies found the umbilical artery $\mathrm{pH}$ of the phenylephrine and ephedrine group was lower than that of the group receiving phenylephrine alone, but proportions of neonates with an umbilical artery $\mathrm{pH}<7.2$ were not different between the two groups even though the study population was too small to obtain adequate statistical power [6,7]. Meta-analysis by Veeser et al. [12] demonstrated that ephedrine use increased the risk of fetal acidosis (defined by an umbilical artery $\mathrm{pH}<7.2$ ) and lowered BE values. However, to my knowledge, there has been no meta-analysis comparing the incidence of fetal acidosis in the phenylephrine and ephedrine group with that in the phenylephrine group.

A systematic review that analyzed 481,753 infants demonstrated that a low $\mathrm{pH}$ of the umbilical artery had a strong association with neonatal mortality and morbidity (hypoxic ischemic encephalopathy, seizures, intraventricular hemorrhage, periventricular leucomalacia, and cerebral palsy) [13]. In our study, there were no significant neonatal adverse outcomes between the two groups. This finding may be associated with the lack of an increase of neonates with low umbilical artery $\mathrm{pH}$ in the combination phenylephrine-ephedrine group compared to the phenylephrine group [6,7]. However, the proportion of neonates with adverse outcomes in our study was small $(0.1-0.3 \%)$. Therefore, no definite conclusion about the impact of vasopressor change on neonatal outcomes could be drawn.

Another method of newborn evaluation is the Apgar score. Though 60 years have passed since the Apgar scoring system was developed by Virginia Apgar, the Apgar score remains an important method for the early detection of infants at risk for serious and fatal conditions $[14,15]$. There were no differences in Apgar scores and the risk of low Apgar scores between the phen- 
ylephrine and ephedrine groups and among the phenylephrine, ephedrine and combination of phenylephrine and ephedrine groups [3,4,6,7,16-20]. However, the sample sizes of these studies may be too small to detect differences in Apgar scores.

The correlation of umbilical artery $\mathrm{pH}$ and Apgar score is unclear. An Apgar scores less than 7 at 5 min neonatal intensive care unit admission and assisted neonatal ventilation had significant inverse relationships with both umbilical artery $\mathrm{pH}$ and $\mathrm{BE}$ $(\mathrm{P}<0.0001)$ in a study of term singleton births with no major abnormalities [21]. However, only a small portion of neonates with low 5 min Apgar scores had metabolic acidosis evidenced by cord $\mathrm{pH}[22]$.

Known risk factors for low Apgar scores include preterm birth, postterm birth, low birth weight, small for gestational age, congenital malformation, and maternal smoking during pregnancy [23-25]. We excluded most risk factors in our study.

Median values of $1 \mathrm{~min}$ Apgar scores in both groups were similar, but the incidence of 1 min Apgar scores less than 7 was higher in the combination phenylephrine and ephedrine group than it was in the phenylephrine group in our study. We evaluated low-risk parturients, but depression of fetal $\mathrm{pH}$ caused by ephedrine combined with phenylephrine could increase the incidence of low 1 min Apgar scores when parturients have unanticipated risks, like a nuchal cord. However, the effect of low umbilical artery $\mathrm{pH}$ on Apgar scores presumably caused by ephedrine seemed to be temporary in our study. Median values of 5 min Apgar scores and the incidence of low 5 min Apgar scores were similar in both groups. Richardson et al. [26] reported a small drop in umbilical artery $\mathrm{pH}$, and $\mathrm{BE}$ was generally well tolerated, with no difference in incidence of 5 min Apgar scores $<7$.

We used $10 \mathrm{mg}$ of heavy bupivacaine for spinal anesthesia. Low-dose bupivacaine between 5-7 mg may provide adequate analgesia for cesarean delivery and reduce consumption of vasopressors [27]. In addition, we used vasopressors prophylactically. A relatively large dose of bupivacaine and the prophylactic use of a vasopressor could increase the total infused dose of the vasopressor. If we performed low-dose spinal anesthesia, the ephedrine consumption would be reduced, and a proportion of low Apgar scores may be reduced as well. However, low-dose spinal anesthesia could increase the risk of intraoperative pain and an incomplete motor block [27,28].

Even though the ephedrine in the combination phenylephrine and ephedrine group could depress umbilical artery $\mathrm{pH}$, it did not appear to reduce the median value of $5 \mathrm{~min}$ Apgar scores in our study. The five-minute Apgar score was a better predictor of neonatal outcome than umbilical artery $\mathrm{pH}$, even for newborn infants with severe acidemia [29]. In accordance with this finding, neonatal outcomes of the two groups were not significantly different in our study. However, the Apgar score may be inappropriate for predicting long-term neurologic outcomes of these neonates [25].

Our study had several limitations. First, the mean age of the phenylephrine group was older than that of the combination phenylephrine and ephedrine group. This trend reflects the rapid aging of parturient patients in Korean society. However, the age difference between the groups was only 0.6 years, and previous studies reported the age range that was a risk factor for a low Apgar score is $<19$ years or $>44$ years, and we excluded such a range of age in our study population $[24,30]$. Second, our study had a small number of infants with low 5 min Apgar scores and adverse neonatal outcomes. During the periods of four years, only 8 with $5 \mathrm{~min}$ Apgar scores $<7$ and 18 with adverse neonatal outcomes were observed when evaluating the 3,761 infants born in our hospital.

In conclusion, conversion from the combination of phenylephrine and ephedrine to phenylephrine alone as a prophylactic anti-hypotensive drug during spinal anesthesia for cesarean section in low-risk pregnancy was associated with a significant decrease in the incidence of 1 min Apgar $<7$, but no decreases in the incidence of 5 min Apgar $<7$ or neonatal outcomes were found. These results could indicate that when used in cesarean section, ephedrine can cause transient low Apgar scores of neonates in low-risk pregnancies. This is the first study to report such an association. Further prospective research evaluating both the umbilical artery acid-base balance and neonatal outcomes according to the use of different vasopressors will be necessary to confirm this finding.

\section{References}

1. Rout CC, Rocke DA, Levin J, Gouws E, Reddy D. A reevaluation of the role of crystalloid preload in the prevention of hypotension associated with spinal anesthesia for elective cesarean section. Anesthesiology 1993; 79: 262-9.

2. Banerjee A, Stocche RM, Angle P, Halpern SH. Preload or coload for spinal anesthesia for elective Cesarean delivery: a meta-analysis. Can J Anaesth 2010; 57: 24-31.

3. Prakash S, Pramanik V, Chellani H, Salhan S, Gogia AR. Maternal and neonatal effects of bolus administration of ephedrine and phenylephrine during spinal anaesthesia for caesarean delivery: a randomised study. Int J Obstet Anesth 2010; 19: 24-30.

4. Dyer RA, Reed AR, van Dyk D, Arcache MJ, Hodges O, Lombard CJ, et al. Hemodynamic effects of ephedrine, phenylephrine, and the coadministration of phenylephrine with oxytocin during spinal anesthesia for elective cesarean delivery. Anesthesiology 2009; 111: 753-65. 
5. Ngan Kee WD, Khaw KS, Tan PE, Ng FF, Karmakar MK. Placental transfer and fetal metabolic effects of phenylephrine and ephedrine during spinal anesthesia for cesarean delivery. Anesthesiology 2009; 111: 506-12.

6. Cooper DW, Carpenter M, Mowbray P, Desira WR, Ryall DM, Kokri MS. Fetal and maternal effects of phenylephrine and ephedrine during spinal anesthesia for cesarean delivery. Anesthesiology 2002; 97: 1582-90.

7. Ngan Kee WD, Lee A, Khaw KS, Ng FF, Karmakar MK, Gin T. A randomized double-blinded comparison of phenylephrine and ephedrine infusion combinations to maintain blood pressure during spinal anesthesia for cesarean delivery: the effects on fetal acid-base status and hemodynamic control. Anesth Analg 2008; 107: 1295-302.

8. Ross MG, Gala R. Use of umbilical artery base excess: algorithm for the timing of hypoxic injury. Am J Obstet Gynecol 2002; $187:$ 1-9.

9. Low JA, Panagiotopoulos C, Derrick EJ. Newborn complications after intrapartum asphyxia with metabolic acidosis in the term fetus. Am J Obstet Gynecol 1994; 170: 1081-7.

10. van den Berg PP, Nelen WL, Jongsma HW, Nijland R, Kollee LA, Nijhuis JG, et al. Neonatal complications in newborns with an umbilical artery $\mathrm{pH}<7.00$. Am J Obstet Gynecol 1996; 175: 1152-7.

11. Cooper DW, Gowni RR. Impact of changing from ephedrine to phenylephrine as the first-line vasopressor during urgent caesarean section. Int J Obstet Anesth 2006; 15: 339-40.

12. Veeser M, Hofmann T, Roth R, Klöhr S, Rossaint R, Heesen M. Vasopressors for the management of hypotension after spinal anesthesia for elective caesarean section. Systematic review and cumulative meta-analysis. Acta Anaesthesiol Scand 2012; 56: 810-6.

13. Malin GL, Morris RK, Khan KS. Strength of association between umbilical cord pH and perinatal and long term outcomes: systematic review and meta-analysis. BMJ 2010; 340: c1471.

14. Apgar V. A proposal for a new method of evaluation of the newborn infant. Curr Res Anesth Analg 1953; 32: 260-7.

15. Moster D, Lie RT, Irgens LM, Bjerkedal T, Markestad T. The association of Apgar score with subsequent death and cerebral palsy: A population-based study in term infants. J Pediatr 2001; 138: 798-803.

16. Ayorinde BT, Buczkowski P, Brown J, Shah J, Buggy DJ. Evaluation of pre-emptive intramuscular phenylephrine and ephedrine for reduction of spinal anaesthesia-induced hypotension during Caesarean section. Br J Anaesth 2001; 86: 372-6.

17. Adigun TA, Amanor-Boadu SD, Soyannwo OA. Comparison of intravenous ephedrine with phenylephrine for the maintenance of arterial blood pressure during elective caesarean section under spinal anaesthesia. Afr J Med Med Sci 2010; 39: 13-20.

18. Ngan Kee WD, Khaw KS, Lau TK, Ng FF, Chui K, Ng KL. Randomised double-blinded comparison of phenylephrine vs ephedrine for maintaining blood pressure during spinal anaesthesia for non-elective Caesarean section*. Anaesthesia 2008; 63: 1319-26.

19. Ngan Kee WD, Khaw KS, Tan PE, Ng FF, Karmakar MK. Placental transfer and fetal metabolic effects of phenylephrine and ephedrine during spinal anesthesia for cesarean delivery. Anesthesiology 2009; 111: 506-12.

20. Jung SW, Kim EJ, Min BW, Ban JS, Lee SG, Lee JH. Comparison of Maternal and Fetal Effects of Ephedrine and Phenylephrine Infusion during Spinal Anesthesia for Cesarean Section. Korean J Anesthesiol 2006; 51: 335-42.

21. Victory R, Penava D, Da Silva O, Natale R, Richardson B. Umbilical cord pH and base excess values in relation to adverse outcome events for infants delivering at term. Am J Obstet Gynecol 2004; 191: 2021-8.

22. Sykes GS, Molloy PM, Johnson P, Gu W, Ashworth F, Stirrat GM, et al. Do Apgar scores indicate asphyxia? Lancet 1982; 1: 494-6.

23. Committee on Obstetric Practice, ACOG; American Academy of Pediatrics; Committee on Fetus and Newborn, ACOG. ACOG Committee Opinion. Number 333, May 2006 (replaces No. 174, July 1996): The Apgar score. Obstet Gynecol 2006; 107: 1209-12.

24. Thorngren-Jerneck K, Herbst A. Low 5-minute Apgar score: a population-based register study of 1 million term births. Obstet Gynecol 2001; 98: 65-70.

25. Nelson KB, Ellenberg JH. Apgar scores as predictors of chronic neurologic disability. Pediatrics 1981; 68: 36-44.

26. Richardson BS, Czikk MJ, daSilva O, Natale R. The impact of labor at term on measures of neonatal outcome. Am J Obstet Gynecol 2005; 192: 219-26.

27. Roofthooft E, Van de Velde M. Low-dose spinal anaesthesia for Caesarean section to prevent spinal-induced hypotension. Curr Opin Anaesthesiol 2008; 21: 259-62.

28. McNaught AF, Stocks GM. Epidural volume extension and low-dose sequential combined spinal-epidural blockade: two ways to reduce spinal dose requirement for caesarean section. Int J Obstet Anesth 2007; 16: 346-53.

29. Casey BM, McIntire DD, Leveno KJ. The continuing value of the Apgar score for the assessment of newborn infants. N Engl J Med 2001; 344: 467-71.

30. Serunian SA, Broman SH. Relationship of Apgar scores and Bayley mental and motor scores. Child Dev 1975; 46: 698-700. 